\title{
Direito Constitucional, Pandemia Globalização
}

\author{
Francisco Balaguer Callejón* \\ Universidad de Granada, Departamento de Derecho Constitucional, Granada, España.
} (iD https://orcid.org/oooo-0001-8084-789o

\begin{abstract}
Resumo: Neste trabalho são analisadas a crise sanitária e a relação com o Direito Constitucional e com a globalização. Confirma-se que as tendências de aceleração da globalização são as que se impõem, não obstante a intervenção do Estado no controle da crise sanitária possa dar a impressão equivocada de que haverá um fortalecimento dos Estados no futuro. Analisa-se, também, a relação entre a crise sanitária e os movimentos e lideranças populistas. Argumenta-se que os anticorpos que historicamente se desenvolveram contra o fascismo não são tão operativos contra o populismo porque foram orientados para controlar a ação do Estado, enquanto o populismo tem se caracterizado justamente pela inação do Estado diante de uma crise que requer uma intervenção decidida dos poderes públicos para preservar os direitos à saúde e à vida dos cidadãos.
\end{abstract}

Palavras-chave: Crise Sanitária. Direito Constitucional. Globalização. Populismo. Democracia. Empresas de tecnologia.

\footnotetext{
* Catedrático de Derecho Constitucional de la Universidad de Granada y Catedrático Jean Monnet "ad personam” de Derecho Constitucional Europeo y Globalización. E-mail: balaguer@ugr.es
}

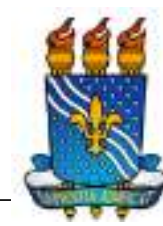

UNIVERSIDADE FEDERAL DA PARAÍBA

Programa de Pós-Graduação em Ciências Jurídicas 


\title{
Direito Constitucional, Pandemia e Globalização ${ }^{1}$
}

\author{
Francisco Balaguer Callejón
}

\section{CRISE SANITÁRIA E DIREITO CONSTITUCIONAL}

Uma pessoa compra um animal selvagem para consumo alimentar em um mercado de uma cidade na China. Um ato aparentemente tão inócuo como esse gera uma infecção terrível que não é o simples resultado de uma ação individual, mas de um comportamento coletivo destrutivo que criou as condições que tornam possível que os vírus de algumas espécies animais possam contagiar os seres humanos. São os danos ambientais que temos provocado, com a redução progressiva da biodiversidade, que tem levado à extinção de espécies animais que serviam de escudo contra a propagação de doenças às pessoas.

A infecção, o vírus, deve ser diferenciada da crise sanitária ${ }^{2}$. Mãos humanas também intervieram na infecção, como acabamos de indicar, devido a danos ambientais. Mas o vírus é um fato físico que poderia ter sido contido de forma mais eficaz, evitando sua disseminação. O não o ter feito assim, ou tê-lo feito de outra forma, em função das respostas sociais e políticas ante o vírus, que como tal resposta já não é um fato físico, mas social; é o que tem causado a crise sanitária, com o impacto diferenciado em diferentes países. Uma crise sanitária mundial de dimensões ainda imprevisíveis, mas que, no momento da escrita destas linhas, já afeta mais de nove milhões de pessoas, enquanto o número de mortes está próximo a quinhentos mil.

\footnotetext{
${ }^{1}$ Tradução de Fernando Joaquim Ferreira Maia, Jailton Macena de Araújo e Maria Creusa de Araújo Borges.

${ }^{2}$ Cf. Sobre a crise sanitária Callejón (2020).
} 
Metade da população mundial foi ou está confinada para evitar a propagação da epidemia e não sabemos a extensão da crise econômica que está sendo gerada.

Este é um exemplo da interconexão e interdependência tão extremas que a globalização tem gerado entre os diversos países do mundo. As previsões econômicas estão sendo atualizadas com uma linha de queda que pode piorar, na medida em que não se controle de pronto a doença. Ao mesmo tempo, e esse é o aspecto positivo, dispomos de mais informações do que em outros períodos históricos, meios muito mais eficazes para fazer frente a estas situações e um nível científico que torna previsível, não apenas um controle efetivo em um tempo relativamente curto (de ponto de vista da saúde), mas também o desenvolvimento de vacinas que evitem que o vírus continue a ser uma ameaça no futuro.

Destas situações derivam-se também consequências constitucionais. Por um lado, se as perspectivas econômicas se deterioram, é previsível que os Estados tenham que limitar os direitos sociais, como já o tem feito em outras ocasiões devido aos ajustes orçamentários que terão de enfrentar. Novamente, nos encontramos, em muitos países, com um enfraquecimento da normatividade da Constituição em favor de uma interpretação econômica (CALLEJÓN, 2013) que já nada tem a ver com a "constituição econômica" do Estado nacional, na qual os fatores de trabalho e capital se ajustavam e se equilibravam dentro do marco constitucional (CALLEJÓN, 2019).

Por outro lado, as medidas que alguns Estados democráticos estão adotando implicam na implementação de normas emergenciais que afetam os direitos fundamentais de amplos setores da população, impedindo sua liberdade de locomoção, acesso a centros e espaços públicos, suspensão de atividades acadêmicas, etc. A preservação da vida e da saúde das pessoas assim o exige e não há o que se possa opor em face destas medidas do ponto de vista da ponderação constitucional de valores, as quais devem ser realizadas em momentos especiais como este. Mas não deixa de ser um passo a mais em direção a um direito constitucional cada vez mais privado das condições de 
"normalidade constitucional" que foram definidas por tempo distinto, o das constituições normativas da segunda metade do século XX, as quais, apesar de existirem dentro do equilíbrio de terror próprio, típico dos blocos mundiais da época, ordenaram seu espaço nacional sem grandes interferências externas.

Neste século XXI, que começou no seu primeiro ano de vida com o terrível atentado às Torres Gémeas, as condições de normalidade constitucional têm sido escassas. As crises, pelo contrário, tem sido frequentes e tem se sucedido uma após a outra sem dar muita trégua. Desde crises clássicas agora reformuladas e, até certo ponto inéditas, nessa reformulação (a crise da democracia representativa e do Estado liberal, agora convertida em uma crise da democracia e do Estado tout court) até crises verdadeiramente sem precedentes na história do constitucionalismo, como é o caso do impacto constitucional da recente crise financeira ou da crise democrática e constitucional gerada pelas empresas de tecnologia através das redes sociais e da utilização da internet, as quais incidem nos processos comunicativos e, especificamente, na comunicação política e na configuração do espaço público.

Movimentos nacionalistas e populistas ${ }^{3}$, que questionam a democracia constitucional, contribuem para enfraquecer o constitucionalismo, ampliando a incidência sobre o sistema constitucional das crises humanitárias geradas pelas guerras ou pelas desigualdades econômicas ou utilizando politicamente o terrorismo para gerar xenofobia. A atenção obsessivamente prioritária aos interesses nacionais, com exclusão de qualquer solidariedade global ou supranacional, acaba sendo uma frente de resistência (essencialmente retórica) contra a globalização, que se manifesta em

3 Quanto a este último, como bem diz Häberle (2018), não devemos permitir que o populismo se aproprie de um nome que tem tanto significado para o constitucionalismo: "Recuso-me a dar a palavra populus aos populistas. Pensemos em Cícero e sua res publica, res populis, nos romanos com seu senatus populus romanus, no não menos famoso we the people, na inscrição do Reichstag "o povo alemão", ou no fato de que, na maioria Estados, se considera que o Judiciário se expressa "em nome do povo". 
nível regional ou estatal, cada vez que se levanta uma oportunidade de entoar o cântico a favor da nação "primeiro" ou "acima de tudo". Como já aconteceu em outros períodos históricos, não se pretende, na realidade, proteger o património nacional ou a própria cultura mas, pelo contrário, abrir as portas à exploração dos recursos e das pessoas pelas oligarquias nacionais, como evidencia a escassa preocupação em relação ao meio ambiente ou aos direitos trabalhistas, expressa pelos líderes populistas.

O motivo pelo qual o constitucionalismo enfrenta uma hora crítica não é a do reaparecimento em cena das crises clássicas, mas sim a da sua mutação genética, bem como o desenvolvimento de novas crises e, sobretudo, de novos contextos críticos. As crises atuais são uma espécie de vírus mutante. Eles surgiram em outros períodos históricos do Estado, os quais dispunham dos instrumentos para canalizá-los através de uma constituição que ordenava o espaço e o tempo. Isso já se refletia nas conotações da lei no Estado liberal: a generalidade, como regulação da totalidade dos sujeitos do território e a abstração como ordenação de todas as situações vitais desses sujeitos. Agora, os fatores de crise foram desconectados do Estado de tal forma que não podem mais ser integralmente ordenados por meio de instrumentos estatais.

Tudo isto faz parte da zona obscura, das sombras da globalização. Não porque o Estado seja a melhor organização possível, mas porque era uma organização submetida à Constituição e não há nada que se lhe pareça que possa substitui-lo no tempo e no espaço da globalização. Mas a outra face dessas sombras são as luzes que projetam esta debilidade do Estado sobre as novas crises e sobre as velhas crises mutantes: a dimensão dessas crises e sua capacidade de afetar os direitos constitucionais é potencialmente menor na medida em que a capacidade de ação do Estado e do seu poder político também o é4. Uma parte dos perigos que aparentemente nos ameaçam são, na

4 Cf. do autor "A crise da democracia na época de Weimar e no século XXI" atualmente no prelo no Brasil. 
realidade, uma retórica vazia cuja finalidade essencial é a da reivindicação eleitoral.

Com efeito, os anos de presidência de Trump foram impregnados de uma retórica que não implementou nenhuma de suas grandes ameaças, como construir o muro na fronteira com o México ou alterar o curso da globalização econômica. Mas tampouco se deve menosprezar o sentido e a orientação dessa retórica: ela enfraquece as instituições constitucionais forjadas em uma longa luta do constitucionalismo pela liberdade, como é o caso do judiciário ou da imprensa livre, e contribui para minar os direitos das minorias e, principalmente, dos imigrantes, setor mais vulnerável da sociedade, favorecendo sua exploração. Não é uma retórica inócua ou sem sentido. É extremamente perigosa para os valores constitucionais, embora não tenha o potencial de destruir todo o sistema constitucional como em outros tempos históricos.

Por outro lado, o fracasso do Estado diante da globalização traz em si a fragilidade de um constitucionalismo que nasceu da luta contra o poder do Estado absoluto5 e que se consolidou na própria configuração do Estado como Estado constitucional. O direito constitucional do século XXI está impregnado de conceitos que faziam sentido há duzentos anos e que hoje constituem um obstáculo à construção de um direito constitucional adaptado ao seu tempo. Esses conceitos, em grande medida defasados, são também o canal através do qual podem entrar as correntes populistas e nacionalistas, as quais os reinterpretam de acordo com seus interesses no sentido de desvirtuar o verdadeiro sentido dos princípios e valores constitucionais essenciais (CALLEJÓN, 2020a). O constitucionalismo de nosso tempo segue vinculado de modo indissolúvel ao sistema conceitual do Estado nacional e isso o impede de encontrar os

\footnotetext{
5 Em relação aos direitos, como indica Paolo Ridola (1999, p. 138), desapareceram os tronos frente os quais se definiu o constitucionalismo liberal estabelecendo garantias contra o Estado absoluto; agora são outras formas de opressão, não menos temíveis, as que tem de enfrentar um constitucionalismo, que já não pode mais se basear na mera defesa contra agressões externas do poder estatal, mas que deve promover a efetivação dos direitos.
} 
caminhos pelos quais poderia caminhar para uma maior densidade constitucional da globalização.

\section{PANDEMIA E CRISE SANITÁRIA: A RESPOSTA POPULISTA À PANDEMIA}

A humanidade inteira está vivendo uma situação extremamente dramática, com uma pandemia de alcance global que se espalha muito rapidamente por todo o mundo. A maior parte da atividade produtiva em muitos países foi paralisada, gerando uma crise econômica igualmente terrível. Em todo o mundo, medidas de distanciamento social são necessárias e, onde quer que o "novo normal" possa chegar, paisagens e cenas evidenciam que nada é normal e nada voltará a sêlo até que possamos ter uma vacina ou um tratamento plenamente eficaz contra o vírus. Vivemos com essa esperança, assumindo como provisórios novos hábitos e padrões de conduta exigidos pelas medidas de proteção à saúde.

Do ponto de vista constitucional, são muitas as áreas onde a crise sanitária teve e continua a ter impacto. A mais visível, matéria tradicional da teoria das fontes do Direito, é a das situações excepcionais sujeitas a decisões e a normas de emergência (que tradicionalmente tem sido contra legem por falta de regulamentação específica, mas que em alguns sistemas constitucionais dispõem canais constitucionais preestabelecidos). Há que se recordar as três condições essenciais que sempre foram atribuídas a essas medidas emergenciais: a primeira delas seu caráter provisório, a ponto de não ser necessária uma decisão expressa para sua perda de vigência, a qual se produz no momento em que as circunstâncias excepcionais terminam. Em segundo lugar, a sua sujeição ao princípio da proporcionalidade, que deve nortear sempre as decisões que são adotadas. Em terceiro lugar, a permanência dos controles estabelecidos pelo ordenamento e, em particular, o controle judicial. 
A preservação da vida e da saúde das pessoas deve prevalecer neste tipo de situação sobre qualquer outro bem ou direito (sempre de acordo com o princípio da proporcionalidade) e, por esse motivo, nos Estados democráticos, se tem adotado medidas de restrições de direitos que estão sendo endossadas até agora pelas jurisdições constitucionais, desde o Tribunal Constitucional espanhol (ATC de 30 de março de 2020) até a Suprema Corte dos Estados Unidos (South Bay United Pentecostal Church, et al., Applicants v. Gavin Newsom, Governador da Califórnia, et al. 26 de maio de 2020).

Isso é algo não tem entendido os dirigentes populistas e isso talvez explique que neste momento os países governados por esses dirigentes sejam precisamente aqueles que apresentam maior incidência da pandemia. Para compreender o que o populismo está fazendo ao mundo, pode ser bom voltar ao seu precedente mais prejudicial, o fascismo. Precisamente no ano passado comemoramos o centenário da Constituição de Weimar, um momento muito oportuno para a reflexão sobre o que o período de Weimar significou para o constitucionalismo, uma época na qual os movimentos fascistas lutavam pela conquista do poder do Estado, o que continuou sendo um centro de poder real e diante do qual se colocaram como uma alternativa global a outros movimentos sociais e políticos ${ }^{6}$.

No momento atual, com líderes populistas que chegaram ao poder em países relevantes como Estados Unidos, Brasil ou Reino Unido, o olhar se volta inevitavelmente para Weimar para determinar até que ponto se estão reproduzindo as condições históricas daquele período. De Weimar até agora, desenvolveram-se três "anticorpos" contra o fascismo, começando pelo primeiro e mais relevante, a globalização e a crescente fragilidade do Estado, submetido a agentes globais que não pode controlar e que determinam em grande medida as suas políticas. A essa debilidade do Estado unem-se outros anticorpos como a integração supranacional, no caso dos países

${ }^{6}$ Cf. do autor "A crise da democracia na época de Weimar e no século XXI", atualmente no prelo no Brasil. 
europeus, e a configuração interna da ordem constitucional por meio de constituições normativas, que estabelecem limites jurisdicionais ao poder do Estado.

Esses anticorpos são fundamentais frente as tendências totalitárias, mas todos eles estão orientados a controlar $a$ ação do Estado. O fascismo não tem mais, com um Estado fraco, a mesma capacidade para impor sistemas totalitários ou para provocar guerras terríveis como na época de Weimar. O controle supranacional (relativamente efetivo, sem dúvida) é outro fator a ser considerado para evitar uma involução democrática dessa natureza, assim como o é, igualmente, a jurisdição constitucional.

Agora, se analisarmos o que aconteceu com esses líderes populistas, impulsionados por grandes empresas de tecnologia que controlam aplicativos de redes sociais e de Internet, sua promoção ao poder tem se orientado mais no sentido de bloquear a política e de impedir a ação do Estado - em benefício dessas grandes empresas, impedindo os controles públicos sobre elas. Com uma evidente exceção, nos dias de hoje em que se debate o "imposto do google", a de pedir que a Administração Trump atue, mas para obstruir ou impedir os controles que são realizados sobre essas empresas fora das fronteiras dos Estados Unidos, por parte da União Europeia.

Qual é a grande lição (ou ao menos uma das grandes lições) que podemos aprender da crise sanitária em relação ao direito constitucional? Pois, sem dúvida, o fato de que esses três anticorpos podem ser muito úteis para controlar a ação do Estado, mas não são tão úteis para controlar a inação do Estado. Podem evitar uma involução democrática que leve à implantação de regimes totalitários e que provoquem guerras como ocorreu com o fascismo, mas não podem impedir que a inação do Estado cause danos terríveis a uma sociedade que confia no poder público para enfrentar situações excepcionais, nas quais necessita de proteção.

Neste ponto é fundamental que reiteremos a diferença entre a epidemia como fato biológico e a crise sanitária. Como indicamos, a epidemia não é simplesmente fruto do acaso, mas também tem a ver 
com a relação dos seres humanos com a natureza. Tem a ver com a deterioração do meio ambiente e, especificamente, da biodiversidade, que tem causado o desaparecimento de espécies animais que serviam de escudo protetor contra a transmissão de infecções. Ainda assim, a resposta social e política à epidemia como fato biológico é fundamental para compreender o alcance da crise sanitária. Essa resposta foi especialmente caótica nos três grandes países com líderes populistas mencionados anteriormente. Dois deles (Trump e Bolsonaro) ainda continuam boicotando as políticas de sua própria equipe técnica, responsável por enfrentar a crise sanitária, bem como dos governadores estaduais, apesar do número oficial assustador de infecções e mortes. Quanto a Johnson, embora tenha corrigido a política desumana inicial de "imunidade de grupo", ele mergulhou seu país em uma situação terrível do ponto de vista humanitário e econômico, que as autoridades sanitárias estão tentando corrigir.

O que a crise sanitária nos evidencia, a partir de uma perspectiva constitucional, é que temos desenvolvido anticorpos para controlar a ação do Estado, evitando assim a repetição das brutalidades fascistas, mas esses anticorpos não nos servem para controlar a inação do Estado, característica de alguns movimentos e líderes populistas de nosso tempo. Quem pensava, como no caso das empresas de tecnologia que impulsionaram esses dirigentes, que bloquear a política e a ação do poder público era uma boa ideia, agora pode comprovar, de maneira trágica, que não era em absoluto. Esperamos que esta lição dramática sirva para que no futuro, se evitem estas tentações de promover o populismo para favorecer interesses particulares em detrimento da sociedade como um todo. Que a frente de um pais da tradição democrática dos Estados Unidos esteja uma personagem como Donald Trump é algo pelo que tem se que se exigir responsabilidade a quem, através da Cambridge Analytica e do Facebook fizeram uma campanha eleitoral irregular em seu favor através do envio de propaganda subliminar personalizada que favoreceu sua vitória. 
Talvez os eleitores estadunidenses tenham em conta este ano o conselho que o The Economist deu, em 19 de junho, aos eleitores ingleses em relação à desastrosa administração de Boris Johnson: "The pandemic has many lessons for the government, which the inevitable public inquiry will surely clarify. Here is one for voters: when choosing a person or party to vote for, do not underestimate the importance of ordinary, decent competence (THE ECONOMIST, 2020)."

\section{A ACELERAÇÃO DA GLOBALIZAÇÃO E A CRESCENTE FRAGILIZAÇÃO DO ESTADO}

A globalização alterou o ritmo histórico, acelerou as transformações que se estão gerando em todas as ordens e privou o Estado de seus principais instrumentos para ordenar a política e a economia dentro de suas fronteiras. As duas grandes crises do constitucionalismo do século XXI expressam, entre outras coisas, essa fragilidade do Estado diante dos agentes globais no campo econômico e nos processos comunicativos que definem o espaço nacional da política (Cf. CALLEJÓN, 2018). A terceira crise que estamos experimentando neste momento e que é consequência da epidemia que assola o mundo, poderia ser equivocadamente considerada, a meu ver, como um retorno ao Estado e um freio à globalização, um impulso à "desglobalização". No entanto, os sinais que se transmitem evidenciam o contrário, um aprofundamento nas tendências geradas pela globalização no século XXI (a terceira globalização no sentido moderno) com o incremento da dependência dos Estados em relação aos agentes tecnológicos e econômicos globais.

É certo que são os Estados que estão organizando a resposta à epidemia e que se tem fechado as fronteiras, se tem interrompido abruptamente o intercâmbio econômico se detém inclusive a atividade econômica em muitos países com medidas de confinamento que foram postas em prática pelos Estados. Nessa perspectiva, tanto os órgãos internacionais como os supranacionais estiveram ausentes. No que se 
refere aos internacionais, seu papel não poderia ter sido mais lamentável, incapazes de advertir dos riscos da epidemia e fazendo possível sua propagação pelo mundo. O diretor da OMS, por exemplo, não só indicou em 30 de janeiro de 2020 que "não há motivo para tomar medidas que interfiram nas viagens e no comércio internacional $7^{\prime \prime}$, mas se permitiu fazer uma piada tossindo dizendo "não se preocupem não é Corona" e provocando risos do público ${ }^{8}$. Na fase inicial de desenvolvimento da epidemia, a OMS não só deixou de alertar para a sua gravidade, como até transferiu para a opinião pública mundial uma visão ainda mais equivocada que a as próprias autoridades chinesas emitiram, eliminando em seus comunicados os cuidados que essas autoridades mantinham frente a possível periculosidade do vírus9. Certamente, nada disso justifica a reação posterior do Presidente dos Estados Unidos em deixar de financiar a OMS justamente no momento em que esta organização, apesar de seus desacertos iniciais, é mais necessária ${ }^{10}$. O que o mundo precisa é de uma OMS mais forte, com mais competências e capacidade de prevenir e combater as pandemias, não que a OMS desapareça como tal.

No que se refere aos órgãos supranacionais e, especificamente, à União Europeia, tem estado ausente da gestão da vertente sanitária da crise, permitindo medidas inaceitáveis como o veto inicial de alguns países à exportação de material sanitário para outros da UE, posteriormente levantado ${ }^{11}$, mas que evidenciou a falta de

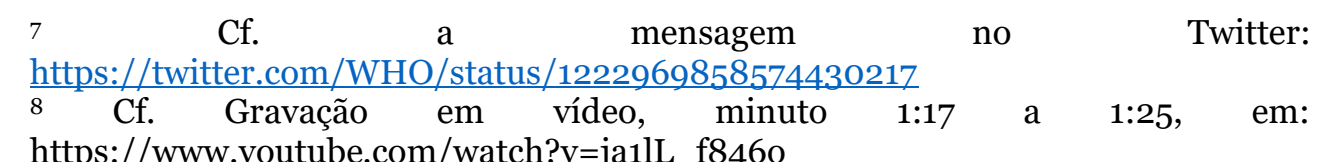

9 Gilsinan (2020) coloca como exemplo um comunicado da OMS de 14 de janeiro, no qual se indicava: "Preliminary investigations conducted by the Chinese authorities have found no clear evidence of human- to-human transmission of the novel \#coronavirus". No entanto, em comparação com a breve declaração da OMS, a do governo chinês continha pelo menos alguma cautela que não foi incluída na da OMS: "The possibility of limited human-to-human transmission cannot be excluded", por mais que "the risk of sustained transmission is low."

${ }_{10}$ Como indica Alistair Bunkall (2020), "There are questions that the World Health Organisation (WHO) needs to answer about its handling of this crisis, but now is surely not the moment".

${ }_{11} \quad$ Cf. https://www.europapress.es/internacional/noticia-alemania-levantarestricciones-envia-italia-millon-mascarillas-frente-coronavirus20200316130441.html 
solidariedade com a Itália, o país que mais sofria com a tragédia. Além disso, a UE gerou preocupação na vertente econômica devido à confusão inicial do BCE (DONCEL, 2020) e ao conflito gerado pela Holanda e Alemanha com os países mais afetados ${ }^{12}$. Felizmente, alguns destes problemas foram resolvidos, mas evidenciam que a lógica de alguns Estados-Membros da UE é radicalmente contrária à necessidade de integração política como a necessária para manter uma moeda comum. A UE não deveria ter lançado o Euro se não havia uma vontade real de integração política e esta deficiência é notada cada vez que há uma crise, agravando-a e gerando um maior eurocepticismo que pode contribuir para destruir totalmente o projeto europeu. $\mathrm{O}$ fracasso dos níveis internacional e supranacional pode dar a falsa impressão de que o Estado nacional vai sair mais forte desta crise. É um erro muito claro se levarmos em conta que o Estado nacional não compete com esses níveis (internacional e supranacional), mas com agentes globais que o privaram de grande parte do seu poder no contexto da terceira globalização. Esses atores globais (empresas de tecnologia e especuladores financeiros) não apenas não perderão nada com a crise, como também experimentarão um impulso significativo. No que diz respeito às empresas de tecnologia, isso é evidenciado pela digitalização progressiva da economia e da sociedade, favorecida pelo confinamento forçado, necessário para conter a propagação da epidemia. Quanto aos especuladores, a pandemia provocou uma crise econômica de dimensões difíceis de calcular, que os favorecerá novamente, como aconteceu com a crise financeira.

As grandes empresas de tecnologia adquiriram um papel especial nesta crise. Não só fornecendo ferramentas de comunicação entre metade da população mundial isolada pelo coronavírus (quase 4 bilhões de pessoas ${ }^{13}$ ), mas também promovendo fórmulas de

\footnotetext{
12 Especialmente lamentável, como infelizmente já se tornou costume, foi a posição holandesa, com algumas declarações do seu ministro da economia que foram qualificadas como "repugnantes" pelo primeiro-ministro de Portugal, que saiu em defesa da Itália e da Espanha, países europeus que de maneira mais trágica estabam sofrendo com a crise sanitária na época (MARTİN DEL BARRIO, 2020).

${ }_{13}$ Cf. https://www.clarin.com/mundo/coronavirus-mitad-poblacion-mundocuarentena-millon-infectados_o_NxbCGGbPp.html
} 
teletrabalho que tiveram que ser implementadas em alguns setores como a educação, justamente pela impossibilidade de desenvolver as atividades no modo presencial. Além disso, as grandes empresas proporcionaram aos governos instrumentos de localização relacionados ao controle da extensão (propagação) da epidemia. Se até agora os governos tem sido incapazes de controlar a violação massiva de direitos que os aplicativos de algumas dessas empresas estão causando, será muito mais difícil fazê-lo no futuro. É muito possível, portanto, que terminem se consolidando as pautas culturais que estão definindo um novo paradigma na relação entre tecnologia e direito constitucional (CALLEJÓN, 202ob).

Para além do fato de que a crise pode contribuir para acelerar as tendências que o processo de globalização tem vindo a manifestar, reduzindo a capacidade de manobra do Estado e o seu poder de decisão no âmbito interno, o certo é que a intervenção do Estado nesta crise evidencia justamente como a dimensão da epidemia se agigantou até converter-se em uma crise econômica e humanitária global, precisamente porque se tem deixado sua solução nas mão de cada um dos Estados.

Assim, encontramos respostas completamente diferentes para um problema comum que deveria ter sido tratado com abordagens comuns. Alguns Estados decidiram inicialmente seguir a estratégia de contenção do vírus por meio da imunidade de grupo, por exemplo, enquanto outros adotaram medidas de supressão com um monitoramento muito detalhado dos casos isolados detectados para prevenir a propagação da epidemia. Alguns Estados optaram pelo confinamento de seus cidadãos em estágios muito iniciais, outros pelo fechamento de fronteiras, outros pela limitação de voos oriundos de países onde havia focos de contágio, outros pela paralisação da atividade econômica, exceto dos serviços essenciais.

Esta diversidade de medidas estende-se às próprias políticas de comunicação relacionadas ao âmbito da epidemia. Alguns Estados forneceram dados questionados, levando em consideração o controle 
das informações que sempre tiveram enquanto regimes autoritários, outros ofereceram dados tardios sobre o número de pessoas afetadas ou sobre o número de mortes causadas pelo vírus. Todavia, ainda hoje assistimos a uma diversidade de dados que não nos permite saber a real dimensão da epidemia. Enquanto alguns Estados incluem apenas aqueles que morreram especificamente do vírus, o que lhes permite oferecer valores percentuais muito baixos sobre o número de afetados, outros incluem todos aqueles que foram diagnosticados, independentemente da causa da morte. A esses números se juntam outros Estados nos quais as mortes ocorreram fora das estruturas hospitalares, mas com sintomas claros de acometimento da doença, embora não tenham havido diagnóstico.

Se nos concentramos nos testes que são realizados, podemos encontrar a mesma situação. Alguns estados relataram números muito baixos de infectados, simplesmente porque não realizam os testes de diagnóstico necessários, enquanto outros fazem esses testes massivamente. Entre os estados europeus com população semelhante podemos encontrar diferenças abismais, de modo que, nos períodos iniciais da pandemia, alguns deles realizaram dez vezes mais exames diagnósticos do que outros. O mesmo cabe dizer para os protocolos que os cidadãos devem seguir para evitar o contágio.

Enquanto alguns Estados (essencialmente os asiáticos) estenderam o uso de máscaras a toda a população junto com outras medidas adicionais de controle, outros consideraram, nos primeiros momentos da pandemia, que essas medidas não eram necessárias e se limitaram a recomendar que sejam evite o contato físico com outras pessoas.

Assim, poderíamos continuar com muitas outras diferenças incompreensíveis na forma como a doença está sendo tratada, mesmo entre países com sistemas sanitários comparáveis, sistemas políticos democráticos e governos sensatos que têm tentado fazer o que é melhor para a população. Se passamos a analisar o comportamento dos políticos que foram promovidos aos seus respectivos postos por algumas empresas de tecnologia por meio de procedimentos 
altamente discutíveis, do ponto de vista de saneamento de campanhas eleitorais (CALLEJÓN, 2019a), nos encontramos agora em uma situação caótica que não se agravou mais graças ao facto de as autoridades sob as suas ordens, encarregadas de controlar eficazmente a epidemia, não lhes terem dado atenção ${ }^{14}$.

Todas essas disfunções, que nos tem conduzido a uma crise mundial de dimensões históricas, poderiam ter sido evitadas se a OMS tivesse competência para emitir resoluções que os Estados tivessem que seguir em relação aos procedimentos de controle da epidemia. Se os Estados houvessem tido diretrizes claras e precisas sobre como a epidemia deveria ser combatida, definindo as ações a serem realizadas para prevenir o contágio e os protocolos a serem seguidos para que essas ações pudessem ser compatíveis em todos os países, possivelmente, a epidemia não teria se expandido e teria sido possível manter também a atividade econômica sem a necessidade de fechar fronteiras e as vias de comunicação entre os diferentes países do mundo. Se um país sabe que nos seus países vizinhos estão sendo adotdas as mesmas medidas, com o mesmo rigor e com os mesmos protocolos, realizando o número de testes diagnósticos necessários, estabelecendo quarentenas para casos positivos e dando informações precisas sobre a extensão da epidemia, não haveria razão para fechar suas fronteiras com esses países.

Precisamente, o fato de se ter tentado controlar a epidemia individualmente, a partir de cada Estado, sem coordenação com os outros, sem diretrizes internacionais claras e sem ações compatíveis, é o que tem levado a um fracasso total no controle global da epidemia e a sua propagação descontrolada. Portanto, o que essa crise sanitária

\footnotetext{
14 No caso de Trump com ameaças de demissão de Anthony Fauci, enquanto Bolsonaro acabou demitindo Luiz Henrique Mandetta, Ministro da Saúde, depois o segundo renunciou e já está se encaminhando para o terceiro ministro da Saúde (Cf. https://cnnespanol.cnn.com/2020/04/13/trump-retuitea-llamado-a-despedir-afauci-en-medio-de-criticas-por-coronavirus/; https://elpais.com/internacional/2020-04-16/el-ministro-de-salud-de-brasilafirma-que-el-presidente-bolsonaro-lo-ha-destituido.html https://elpais.com/internacional/2020-0.5-17/el-choque-con-bolsonaro-por-ladesescalada-y-el-uso-de-un-farmaco-forzo-la-caida-del-titular-de-salud-debrasil.html)
} 
evidenciou não foi a capacidade dos Estados de resolver os problemas globais, mas sua absoluta impotência. Isso não significa que os Estados não tenham que agir e não devam continuar a fazê-lo precisamente para resolver os problemas que eles próprios criaram por não terem pactuado em nível internacional os instrumentos necessários para enfrentar as crises globais. O Estado será sempre o último recurso porque é quem tem poder direto sobre a população, mas esse último recurso não seria necessário ativar, da maneira se tem feito, se tivesse havido um acordo internacional que resolvesse efetivamente o problema sem agravá-lo - a ponto de gerar uma catástrofe humanitária de dimensões aterradoras.

Já podemos tirar algumas conclusões do que aconteceu até agora. A primeira delas tem a ver com a necessidade de consenso internacional para resolver questões de alcance global. A segunda tem a ver com a preocupação no sentido de que, do ponto de vista constitucional, possamos ter, diante de um possível avanço do nacionalismo e do populismo nos países democráticos, como consequência da nova crise econômica que se incubou na crise da saúde. A terceira, com uma extraordinária aceleração da globalização que evidencia que os vencedores desta crise serão justamente aqueles que anteriormente acumularam grande poder como agentes globais: as grandes empresas de tecnologia e a China.

\section{CONCLUSÕES}

Como tivemos oportunidade de constatar neste trabalho, para analisar o impacto da pandemia sobre o direito constitucional e sobre a globalização, temos que partir da prévia diferenciação entre o vírus como fato biológico e a resposta social à pandemia. A epidemia também está relacionada ao comportamento humano porque ocorreu, em grande parte, devido à perda de biodiversidade que geramos com a destruição do meio ambiente. Mas ainda é um fato biológico que temos que contrastar com a crise sanitária que se produziu a partir da resposta social e política ao vírus. Essa crise está sendo mais intensa 
em países governados por líderes populistas. A explicação é relativamente simples: esses líderes foram promovidos por empresas de tecnologia e agentes globais que tinham interesse em bloquear a política, na qual esses líderes se limitavam a administrar o poder do Estado. Comparado com o precedente do fascismo, o populismo se caracteriza justamente por uma dimensão essencialmente retórica que não quer controlar o Estado para desenvolver uma ação política tão destrutiva como a do fascismo, que deu origem a regimes totalitários.

O motivo para essa mudança é que, nos anos transcorridos desde a derrota do fascismo na Segunda Guerra Mundial, certos anticorpos contra o fascismo se desenvolveram. Em primeiro lugar, a própria globalização, que enfraqueceu os Estados, cujo poder é muito menor e pode causar menos danos. Em segundo lugar, onde existe, a integração supranacional e, em terceiro lugar, as constituições normativas do Estado constitucional, com seu sistema de proteção jurisdicional da constituição.

Mas uma das grandes lições que podemos aprender com a atual crise sanitária é que esses três anticorpos podem ser muito úteis para controlar a ação do Estado, mas não são tão úteis para controlar a inação do Estado. Eles podem impedir uma involução democrática que leve à implantação de regimes totalitários e que provoquem guerras como aconteceu com o fascismo, mas não podem impedir que a inação do Estado gere danos terríveis a uma sociedade que confia no poder público para fazer frente a situações excepcionais, como as pandemias, nas quais se necessita proteção especial. Quem pensava, como no caso das empresas de tecnologia que impulsionaram os dirigentes populistas, que bloquear a política e a ação do poder público era uma boa ideia, agora pode comprovar, de maneira trágica, que não o era em absoluto.

Data de Submissão: 10/11/2020

Data de Aprovação: 10/11/2020

Processo de Avaliação: desk review 
Editor Geral: Jailton Macena de Araújo

Editor de Área: Maria Creusa de Araújo Borges

Tradução: Fernando Joaquim Ferreira Maia; Jailton Macena de Araújo; Maria Creusa de Araújo Borges

Assistente Editorial:

\section{REFERÊNCIAS}

BUNKALL, Alistair. Why Trump is cutting WHO funding during a pandemic, Skynews, 15 de abril de 2020. Disponível em:

https://www.msn.com/en-au/news/world/comment-why-trump-iscutting-who-funding-during-a-pandemic/ar-BB12EOJ4?li=AAgfYrC. Acesso em 05 dez. 2020.

CALLEJÓN, Francisco Balaguer, Costituzione economica e globalizzazione, federalismi.it, numero speciale. 5/2019, 25 Ottobre 2019, p. 42-54. Disponível em:

https://www.federalismi.it/ApplOpenFilePDF.cfm?artid=40502\&dp ath $=$ document $\&$ dfile $=25102019205029 . p d f \&$ content $=$ Costituzione $\%$ 2Beconomica\%2Be\%2Bglobalizzazione\%2B\%2D\%2Bstato\%2B\%2D\% 2Bdottrina\%2B\%2D\%2B. Acesso em o5 dez. 2020.

CALLEJÓN, Francisco Balaguer, Crisi sanitaria, globalizzazione e diritto costituzionale, Scritti in onore di Paolo Ridola, Rivista italiana per le scienze giuridiche, Rome, 2020. Disponível em: https://www.rivistaitalianaperlescienzegiuridiche.it/node/268. Acesso em 05 dez. 2020.

CALLEJÓN, Francisco Balaguer, Interpretación constitucional y populismo, Revista de Derecho Constitucional Europeo, n. 33, Enero-Junio de 2020. Disponível em:

https://www.ugr.es/ redce/REDCE33/articulos/o4 BALAGUER.ht m. Acesso em 05 dez. 2020.

CALLEJÓN, Francisco Balaguer, Redes sociales, compañías tecnológicas y democracia, Revista de Derecho Constitucional Europeo, Número 32, julio-diciembre de 2019.

CALLEJÓN, Francisco Balaguer, Una interpretación constitucional de la crisis económica, Revista de Derecho Constitucional Europeo, n. 19/2013. Disponível em: https://www .ugr.es/ redce/REDCE19/articulos/15_F_BALAGUER. htm. Acesso em: 05 dez. 2020.

CALLEJÓN, Francisco Balaguer. Constitution, démocratie et mondialisation. La légitimité de la Constitution face à la crise économique et aux réseaux sociaux, Mélanges en l'honneur du Professeur Dominique Rousseau. Constitution, justice, démocratie. L.G.D.J , Paris $2020 b$. 
CALLEJÓN, Francisco Balaguer. Las dos grandes crisis del constitucionalismo frente a la globalización en el siglo XXI. Nomos: Le attualità nel diritto, Anticipazioni Convegno: Passato, presente e futuro del costituzionalismo e dell'Europa, 2018. Disponível em: http://www.nomos- leattualitaneldiritto.it/wpcontent/uploads/2018/o9/Balaguer_Costituzionalismo.pdf. Acesso em: 19 nov. 2020.

CALLEJON, Francisco Balaguer. Redes sociales, compañías tecnológicas y democracia, Revista de Derecho Constitucional Europeo, Número 32, julio-diciembre de 2019a. Disponível em: https://www.ugr.es/ redce/REDCE32/articulos/O4 F BALAGUER .htm. Acesso em: 05 dez. 2020.

DONCEL, Luis. Lagarde inflama los mercados con un mensaje decepcionante, El País, 13 de marzo de 2020. Disponível em: https://elpais.com/economia/2020-03-13/lagarde-inflama-losmercados-con-un-mensaje-decepcionante.html. Acesso em 5 dez. 2020.

GILSINAN, Kathy. How China Deceived the WHO, The Atlantic, 12 de abr. de 2020. Disponível em:

https://www.theatlantic.com/politics/archive/2020/04/worldhealth-organization-blame-pandemic-coronavirus/609820/. Acesso em 19 nov. 2020

HÄBERLE, Peter. El constitucionalismo como proyecto científico, Revista de Derecho Constitucional Europeo, n. 29, EneroJunio de 2018. Disponível em:

https://www.ugr.es/ redce/REDCE29/articulos/o4 HABERLE.htm . Acesso em: 05 dez. 2020.

MARTÍN DEL BARRIO, Javier. Portugal arremete contra la "repugnante" respuesta de los Países Bajos a la crisis sanitaria, El País, 27 de marzo de 2020. Disponível em:

https://elpais.com/economia/2020-03-27/repugnante-la-criticaportuguesa-contra-el-gobierno-holandes-por-su-respuesta-a-lacrisis-del-coronavirus.html. Acesso em 5 dez. 2020.

RIDOLA, Paolo. Garanzie, diritti e trasformazioni del costituzionalismo, Esperienza, Costitucioni, Storia. Pagine di storia costituzionale, cit., p. 138. Disponível em: https://www.scienzegiuridiche.uniroma1.it/sites/default/files/docen ti/ridola/Ridola garanzie-diritti-etc.pdf. Acesso em 20 nov. 2020.

THE ECONOMIST. Britain has the wrong government for the covid crisis. Politics and pandemics. The economist. 18 jun. 2020. Diponível em: https://www.economist.com/leaders/2020/06/18/britain-has-thewrong-government-for-the-covid-crisis. Acesso em: 19 nov. 2020. 


\title{
Derecho constitucional, Pandemia y globalización
}

\author{
Francisco Balaguer Callejón
}

Resumen: En este trabajo, son analizadas la crisis sanitaria y la relación con el Derecho Constitucional y con la globalización. Se constata como las tendencias de aceleración de la globalización son las que se están imponiendo pese a que la intervención del Estado en el control de la crisis sanitaria pudiera dar la impresión equivocada de que se va a producir un reforzamiento de los Estados en el futuro. Se analiza también la relación entre la crisis sanitaria y los movimientos y líderes populistas. Se argumenta que los anticuerpos que se habían desarrollado históricamente contra el fascismo no son tan operativos contra el populismo porque estaban orientados a controlar la acción del Estado mientras que el populismo se ha caracterizado justamente por la inacción del Estado frente a una crisis que exige una intervención decidida de los poderes públicos para preservar los derechos a la salud y a la vida de los ciudadanos.

Palabras clave: Crisis sanitária. Derecho constitucional. Globalización. Populismo. Democracia. Compañías tecnológicas.

DOI: https://doi.org/10.22478/ufpb.1678-2593.2020v19n42.56459

Conteúdo sob licença Creative Commons: Attribuition-NonCommercial-NoDerivative 4.0 International (CC BY-NC-ND 4.0) 